\title{
Pore-Scale Modeling of Fluid-Rock Chemical Interactions in Shale during Hydraulic Fracturing
}

\author{
Hossein Fazeli,* Veerle Vandeginste, Arash Rabbani, Masoud Babaei,* and Bagus Muljadi \\ Cite This: https://doi.org/10.1021/acs.energyfuels.0c02975 \\ Read Online
}

ACCESS | Lلll Metrics \& More | 回 Article Recommendations | si Supporting Information

\begin{abstract}
During the hydraulic fracturing process in unconventional shale gas reservoirs, chemical interactions between the hydraulic fracturing fluid (HFF) and the shale rock could result in mineral precipitation and dissolution reactions, potentially influencing the gas transport by dissolving or clogging the fractures. The pore-scale distribution of the minerals, especially the highly reactive minerals, such as calcite, in the shale matrix can impact the structural evolution of the shale rocks. In the present study, a pore-scale reactive transport model is built to investigate the impact of the pore-scale distribution of calcite on the structural alteration of the shales. The alteration of the shales is caused by the

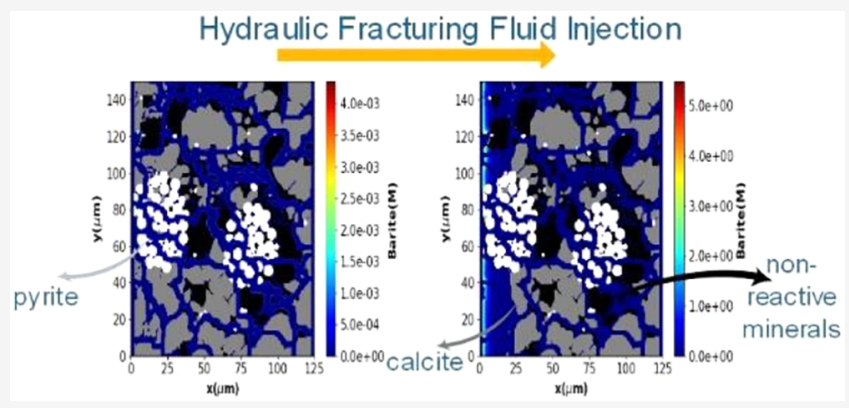
barite precipitation and the dissolution of calcite and pyrite. The simulation results show that the calcite dissolution leads to a permeability enhancement. The permeability enhancement for the shales with coarser calcite grains is more pronounced than that for the shales with finer grains of calcite. The results also indicate that the extent of the permeability enhancement is even more noticeable if the HFF is injected with a higher velocity. The fluid chemistry analysis indicates that the fluid $\mathrm{pH}$ for the shale with the fine grains of calcite is higher than that of the shale with the coarse calcite grains and that the injection of the HFF with a higher flow rate leads to the lower $\mathrm{pH}$ values. The calcite dissolution observed in the simulations mainly occurs near the inlet. For the shale with the finer calcite grains, barite precipitation occurs mostly close to the inlet, but for the shale with coarser calcite grains, barite precipitation extends more into the domain. This penetration depth increases when the HFF is injected with a higher velocity. In addition to the effect of the calcite distribution, we also used the pore-scale model to study the effect of the calcite content on the structural evolution of the shales. The results from these simulations showed that a higher calcite content can result in higher $\mathrm{pH}$ values, higher permeabilities, and more barite precipitation in the domain.
\end{abstract}

\section{INTRODUCTION}

Natural gas is viewed as a reliable energy resource because it has a high energy content and also emits less greenhouse gases, such as $\mathrm{CO}_{2}$, compared to other fossil fuels. ${ }^{1}$ In the U.S., a considerable amount of the increase in the natural gas production has been attributed to the production of gas from shale gas reservoirs. ${ }^{2}$ Some of the formations in Europe, such as Posidonia, Alum, and Bowland-Hodder formations, are also believed to have economic potential for hydrocarbon production. $^{3-5}$

Because of their low permeability, shale gas reservoirs have to be stimulated by hydraulic fracturing, so that the gas entrapped in the tight rocks can flow through the pathways generated during the fracturing process. The fractures in the rock are created by the injection of a fracturing fluid under high pressure. Once injected into the shale reservoir, hydraulic fracturing fluid (HFF) reacts with shale rock where, depending upon the rock mineralogy and the different chemical components in the fracturing fluid, various chemical reactions might occur in the shale fractures and matrices during the fracturing process. ${ }^{6-12}$ These geochemical reactions can change the transport properties of shales, affecting the gas production from shale gas reservoirs. ${ }^{6,8,9,12-17}$ For example, cases have been documented where the production rate decreased significantly within a short time after initial gas recovery from shale gas reservoirs, suggested to be caused by the precipitation of minerals in the fractures and the matrix of fractured shale reservoirs. ${ }^{7,18}$ The chemical reactions between HFF and shales can also influence the chemical composition of the produced water after the fracturing process. ${ }^{13,14}$ Therefore, understanding the chemical reactions between HFF and shales can help better predict the gas productivity and environmental impacts during hydraulic fracturing processes. ${ }^{15}$

Various studies have investigated the effects of the HFFshale chemical interactions on the hydrodynamic properties of shale rocks (such as porosity and permeability) $)^{7,8,19-24}$ and the

Received: September 3, 2020

Revised: $\quad$ May 10, 2021 
flowback water chemistry. ${ }^{15,17,25-32}$ Some of these studies have experimentally and numerically assessed the impact of HFFshale chemical interactions on the alteration of the fracturematrix interfaces at the pore scale (micrometer scale). ${ }^{21,22,24}$ Although formation of this altered layer is a pore-scale feature, it can have large-scale impacts on hydrocarbon recovery because the thickness of this altered zone can influence the transport (advection and diffusion) of hydrocarbons from matrices to fractures in shale formations. ${ }^{22} \mathrm{~A}$ pore-scale parameter that controls the structure of this altered zone (or the reacted shale in general) is the pore-scale distribution of the matrix-forming minerals, especially the highly reactive phases, such as calcite. To our knowledge, there have not been studies systematically evaluating the impact of the pore-scale mineral distribution on the alteration of shale morphology during the HFF-shale chemical interactions. To fill this gap, we built a pore-scale reactive model to simulate the alteration of the shale morphology while reacting with the HFF. We choose pore-scale models because these models can resolve the pore-scale features, such as pore-scale mineral distributions. The main focus of this study is to evaluate the effect of the pore-scale mineral distribution of calcite on the alteration of the shale morphology when the shale rock is exposed to an acidic HFF, which leads to the calcite dissolution. In addition to the effect of the pore-scale mineral distribution of calcite, we also use the built model to investigate the impact of the calcite content on the chemical alteration of the shale rocks at the pore scale. Moreover, because the scale precipitation is another common mineral reaction during HFF-shale interactions, we also include the barite precipitation reaction (a common scale reaction in various fields, ${ }^{33-37}$ including hydraulic fracturing) in the simulations and will investigate how different calcite mineral distributions can impact the location of barite precipitates. We perform these simulations under different transport (flow velocity) conditions. The details of the model setup are discussed in the following sections.

\section{METHODS}

2.1. Pore-Scale Lattice Boltzmann (LB)-Based Reactive Transport Model. The simulator used in this study to perform the reactive transport simulations is based on the LB method, which solves the Navier-Stokes and advection-diffusion-reaction equations. The chemical reaction calculations are performed by PHREEQC, ${ }^{38}$ which has been coupled with the transport solver.

In the pore-scale reactive transport simulations, the concentration of different species are obtained by solving the advection-diffusionreaction equation

$$
\frac{\partial C_{j}}{\partial t}+\nabla\left(-D_{j} \nabla C_{j}+\mathbf{u} C_{j}\right)=R_{j}
$$

where $C_{j}\left(\mathrm{~N} \mathrm{~L}^{-3}\right)$ is the aqueous concentration of the species $j, D_{j}\left(\mathrm{~L}^{2}\right.$ $\left.\mathrm{T}^{-1}\right)$ is the diffusion coefficient of the species $j$, and $R_{j}\left(\mathrm{~N} \mathrm{~L}^{-3} \mathrm{~T}^{-1}\right)$ represents the source or sink term as a result of reactions for the species $j . \mathrm{T}, \mathrm{L}$, and $\mathrm{N}$ refer to the units of the time, length, and amount of substance. In eq $1, R_{j}$ represents the homogeneous reactions. Heterogeneous reactions at the interface between solid and liquid are usually treated as boundary conditions.

In eq 1 , the velocity can be obtained by solving the Navier-Stokes and continuity equations

$$
\begin{aligned}
& \nabla \mathbf{u}=0 \\
& \rho \frac{\partial \mathbf{u}}{\partial t}+\rho \mathbf{u} \nabla \mathbf{u}=-\nabla P+\mu \nabla^{2} \mathbf{u}+\mathbf{F}
\end{aligned}
$$

where $\rho\left(\mathrm{M} \mathrm{L}^{-3}\right)$ is the density, $\mathbf{u}\left(\mathrm{L} \mathrm{T}^{-1}\right)$ is the velocity, $P\left(\mathrm{M}^{1} \mathrm{~L}^{-1}\right.$ $\left.\mathrm{T}^{-2}\right)$ is the pressure, $\mu\left(\mathrm{M}^{1} \mathrm{~L}^{-1} \mathrm{~T}^{-1}\right)$ is the dynamic viscosity, and $\mathrm{F}$ $\left(\mathrm{M}^{1} \mathrm{~L}^{-2} \mathrm{~T}^{-2}\right)$ is the body force.

The Navier-Stokes and advection-diffusion-reaction equations in our pore-scale model are solved using the LB method. In the LB method, the hydrodynamic properties, such as the flow velocity and the concentration of species, are obtained by solving the discretized Boltzmann equation. The discretized LB equation reads ${ }^{39}$

$$
f_{i}\left(\mathbf{x}+\mathbf{c}_{\mathbf{i}} \Delta t, t+\Delta t\right)=f_{i}(\mathbf{x}, t)+\Omega_{i}^{\mathrm{SRT}}(f)+\mathbf{F}_{\mathbf{i}} \Delta t
$$

where

$$
\begin{aligned}
& \Omega_{i}^{\mathrm{SRT}}(f)=\frac{-\Delta t}{\tau}\left(f_{i}-f_{i}^{\mathrm{eq}}\right) \\
& f_{i}^{\mathrm{eq}}=w_{i} \rho\left(1+\frac{\mathbf{u c}_{\mathbf{i}}}{c_{\mathrm{s}}{ }^{2}}+\frac{\left(\mathbf{u c}_{\mathbf{i}}\right)^{2}}{2 c_{\mathrm{s}}{ }^{4}}-\frac{\mathbf{u u}}{2 c_{\mathrm{s}}{ }^{2}}\right) \\
& \mathbf{F}_{\mathbf{i}}=w_{i} \frac{c_{i \alpha}}{c_{\mathrm{s}}{ }^{2}} F_{\alpha} \\
& c_{\mathrm{s}}{ }^{2}=\frac{1}{3}\left(\frac{\Delta x}{\Delta t}\right)^{2}
\end{aligned}
$$

In the above equations, $f_{i}$ is the discretized distribution function, $f_{i}^{\text {eq }}$ is the equilibrium distribution function, $\Delta x$ and $\Delta t$ are the spatial and the temporal increments, $\Omega_{i}^{\mathrm{SRT}}$ is the collision operator, $c_{\mathrm{s}}$ is the lattice speed of sound, $\mathbf{u}$ is the velocity, $\mathbf{F}_{\mathbf{i}}$ is the body force, $c_{i}$ is the discrete velocity, $\rho$ is the density, $\tau$ is the relaxation time, and $w_{i}$ is the weighing coefficients. For solving the flow equation, the $\mathrm{D} 2 \mathrm{Q} 9$ lattices are used. Here, the number 2 in $\mathrm{D} 2 \mathrm{Q} 9$ denotes the number of spatial dimensions (in $x$ and $y$ ), whereas 9 denotes the number of velocities of the set. ${ }^{39}$ The hydrodynamic moments of eq 4 , such as $\mathbf{u}$ and $\rho$, can be acquired from the following equations:

$$
\begin{aligned}
& \mathbf{u}=\frac{1}{\rho} \sum_{i=0}^{8} f_{i} c_{i}+\frac{\mathbf{F} \Delta t}{2 \rho} \\
& \rho=\sum_{i=0}^{8} f_{i}
\end{aligned}
$$

To show that eq 4 can recover the Navier-Stokes equation, an analysis called Chapman-Enskog can be performed. Using this analysis demonstrates that the dynamic viscosity of fluid, $\nu$, can be related to the relaxation parameter through the following relation:

$$
\nu=c_{\mathrm{s}}^{2}\left(\tau-\frac{\Delta t}{2}\right)
$$

The LB equation used to solve the advection-diffusion-reaction equation reads

$$
\begin{aligned}
& g_{i}^{j}\left(\mathbf{x}+\mathbf{c}_{\mathbf{i}} \Delta t, t+\Delta t\right) \\
& \quad=g_{i}^{j}(\mathbf{x}, t)+\Delta t \Omega_{i}^{\mathrm{TRT}, j}(\mathbf{x}, t)+\Delta t \Omega_{i}^{\mathrm{rxn}, j}(\mathbf{x}, t)
\end{aligned}
$$

where

$$
\begin{aligned}
& \Omega_{i}^{\mathrm{TRT}, j}(\mathbf{x}, t)=\frac{-1}{\tau_{+g}}\left(g_{i}^{+j}-g_{i}^{\mathrm{eq}+, j}\right)+\frac{-1}{\tau_{-g}}\left(g_{i}^{-j}-g_{i}^{\mathrm{eq}-, j}\right) \\
& g_{i}^{+}=\frac{g_{i}+g_{-i}}{2}, \quad g_{i}^{-}=\frac{g_{i}-g_{-i}}{2} \\
& g_{i}^{\mathrm{eq}+}=\frac{g_{i}^{\mathrm{eq}}+g_{-i}^{\mathrm{eq}}}{2}, \quad g_{i}^{\mathrm{eq}-}=\frac{g_{i}^{\mathrm{eq}}-g_{-i}^{\mathrm{eq}}}{2} \\
& \Omega_{i}^{\mathrm{rxn}, j}(\mathbf{x}, t)=w_{i} R_{\text {total }}^{j}
\end{aligned}
$$




$$
g_{i}^{\mathrm{eq}, j}=w_{i} C^{j}\left(1+\frac{\mathbf{u c}_{\mathbf{i}}}{c_{\mathrm{s}}^{2}}\right)
$$

where $C^{j}$ is the concentration of the species $j, g_{i}^{j}$ is the discrete distribution function for the species $j, g_{i}^{\mathrm{eq}, j}$ is the equilibrium distribution function of the species $j, \Omega_{i}^{\mathrm{TRT}, j}$ is a two-relaxation-time collision operator in which the symmetric, $g_{i}^{+j}$, and antisymmetric, $g_{i}^{-j}$, distribution functions are used, $\tau_{+}$and $\tau_{-}$are the relaxation parameters for the symmetric part and antisymmetric part, respectively. In the above equations, the subscript $i$ is related to the direction with the velocity $\mathbf{c}_{\mathbf{i}}$ and $-i$ shows the direction with the velocity $-c_{i}$. The lattice structure used for the LB scheme is D2Q5. The contribution of the reactions in the bulk of the fluid and also the reactions at the fluid-mineral interface to the concentration of $j$ th species can be added to the discretized LB equation through the term $R_{\text {total }}^{j}$

$$
R_{\text {total }}^{j}=\frac{C_{\text {reaction }}^{j}-C_{\text {transport }}^{j}}{\Delta t}
$$

where $C_{\text {transport }}^{j}$ is the concentration of the species $j$ after running the transport step. This concentration is then given to the chemical solver PHREEQC $^{38}$ [which has been coupled to the transport solver using the sequential non-iterative approach (SNIA) approach] to compute the new concentration of the species $j$, which is $C_{\text {reaction. In the }}^{j}$ coupling of the transport and reactions, the time step [which is $0.000167(\mathrm{~s})]$ is chosen in a way that the CFL $<1$.

The concentration of the species $j$ can be calculated using the following:

$$
C^{j}=\sum_{i=0}^{4} g_{i}^{j}
$$

Similar to the LB method for flow, performing Chapman-Enskog analysis shows that the following relation exists between the diffusion coefficient for different species and the relaxation parameter:

$$
D=c_{s}^{2}\left(\tau_{-}-\frac{\Delta t}{2}\right)
$$

It should also be pointed out that the reactive transport solver can also track the pore space changes as a result of the precipitation and/or the dissolution of minerals. The change in the pore space is modeled using the static update rules. The pore spaces are updated on the basis of the amount of the volume fraction occupied by solid mineral phases, denoted as $\phi_{\mathrm{m}}$. The pore space is updated when $\phi_{\mathrm{m}}$ reaches a threshold value, $\phi_{\mathrm{m} \text {,thres }}$. When $\phi_{\mathrm{m}} \leq \phi_{\mathrm{m} \text {,thres }}$ at a solid grid cell, the solid grid cell is converted into a fluid grid cell, and when $\phi_{\mathrm{m}}>\phi_{\mathrm{m} \text {,thres }}$ at a liquid grid cell, it is converted into a solid grid cell. ${ }^{40}$ In this study, $\phi_{\mathrm{m} \text {,thres }}$ is 0.5 . It has been shown that taking $\phi_{\mathrm{m} \text {,thres }}$ as 0.5 leads to more accurate solutions for moving boundary problems. ${ }^{40}$

2.2. Shale Geometries. The pore-scale reactive transport simulations are performed for the two-dimensional (2D) and threedimensional (3D) shale geometries (Figures S1-S7 of the Supporting Information). For the $2 \mathrm{D}$ shale geometries, two shale samples with the same calcite content but different calcite spatial distribution patterns are generated. These two spatial distributions for calcite are controlled by the two-point correlation function. Two-point correlation is a measure that shows the amount of spatial independence of a single variable at two different points of the studied domain. ${ }^{41}$ In other words, this function describes what is the probability of two different points to have the same value if there is a specific amount of distance between them. ${ }^{41,42}$ When the distance between the two selected points approaches zero, the probability of them having the same value is at its maximum, while when there is a noticeable gap between the two selected points, their values become almost independent from each other. ${ }^{41,42}$ The domain size of the generated shale geometries is $125 \times 125 \mu \mathrm{m}$ with a resolution equal to $0.5 \mu \mathrm{m}$. To study the effect of the calcite content on the alteration of the shale rocks, one more $2 \mathrm{D}$ shale structure with the higher calcite content is also generated. To generate the reasonable realizations of the organic-rich shale deposits, we have used some image processing steps that are described as follows: Two Gaussian random files with different standard deviations are interpolated and thresholded to mimic the solid texture of the calcite and silicate minerals. ${ }^{43}$ Then, using the watershed segmentation, we have separated the connected elements of calcite and silicate to give them a more grain-like shape. ${ }^{44}$ Afterward, parts of the remaining void space are filled with the clay flakes by thresholding a distance map and adding some levels of noise to imitate a texture of the packed flakes. The remaining void space is assumed to be filled with the porous organic matter, which is called kerogen. Then, some parts of the whole structure are randomly snipped to be embedded by the pyrite framboids because they technically form after the initial deposition of the shale layers. ${ }^{44}$ Finally, while knowing the physically stronger parts of the shale structure that are composed of the pure solid minerals, calcite, silicate, and pyrite, we perform a heuristic fracturing simulation in the three directions: horizontal, $45^{\circ}$, and $135^{\circ}$. The same procedure was used to generate a $3 \mathrm{D}$ shale realization with domain size of $125 \times 125 \times 15$ $\mu \mathrm{m}$. It has been shown that the shale geometries generated using this statistical approach are comparable with the 2D scanning electron microscopy (SEM) images of the real shale samples. ${ }^{45}$ The grain sizes of the generated minerals and the sizes of the generated fractures are within the range of the values reported in the literature. ${ }^{46,47}$ The details of this statistical approach have been described in previous studies by Rabbani et al. ${ }^{45,48}$

\section{SIMULATION SETUP}

The reactions considered in the simulations are the calcite and pyrite dissolution and the barite precipitation. These are some of the commonly observed reactions taking place during the HFF-shale interactions. ${ }^{8,21,22,24}$ Simulations are performed for the shales with coarse and fine calcite fragments, designated as CCS and FCS, respectively. To assess the alteration of the shale sample when the calcite content is higher, we simulate a case with the higher calcite in the shale matrix, designated as HCS. For the case of CCS, we also run a simulation with the higher fluid flow rate to evaluate the effect of transport conditions (more advective transport) on the evolution of the shale structure. Calcite contents for CCS and FCS are the same and equal to $\sim 30 \%$, while the calcite content for HCS is $\sim 63 \%$. The average velocities in the domain for CCS, FCS, and HCS are $6.66 \times 10^{-7}, 8.08 \times 10^{-7}$, and $8.01 \times 10^{-7}(\mathrm{~m}$ $\mathrm{s}^{-1}$ ), respectively. The average velocity of the simulations for CCS with higher injection velocity is $6.66 \times 10^{-5}\left(\mathrm{~m} \mathrm{~s}^{-1}\right)$. We model the flow of an acidic solution, with $\mathrm{pH} 2$, through the fractured shale geometries. The injected fluid is supersaturated with respect to barite, with SI of 1.3. Therefore, the main source of barium and sulfate for the barite precipitation is derived from the injected solution and not from the host rock. The HFF can have high concentration of barium and sulfate if produced waters are diluted and used as the HFF. ${ }^{8}$ The injected HFF composition is given in Table $\mathrm{S} 1$ of the Supporting Information. Preliminary simulations showed that the reaction rate of the minerals, such as silicate and clay, are much slower than calcite during the simulation time scale. Therefore, in the simulations, we treated silicate, clay, and kerogen as non-reactive phases and only calcite, pyrite, and barite were considered as the reactive minerals.

The reaction rates of calcite, pyrite, and barite reactions are calculated on the basis of the following equations: ${ }^{49-51}$

$$
\begin{aligned}
& R_{\text {calcite }}\left(\mathrm{mol} \cdot \mathrm{m}^{-2} \cdot \mathrm{s}^{-1}\right) \\
& \quad=\left(10^{-0.3} a_{\mathrm{H}^{+}}+10^{-5.81}+10^{-3.48} a_{\mathrm{H}_{2} \mathrm{CO}_{3}}\right)\left(1-\Omega_{\text {calcite }}\right)
\end{aligned}
$$



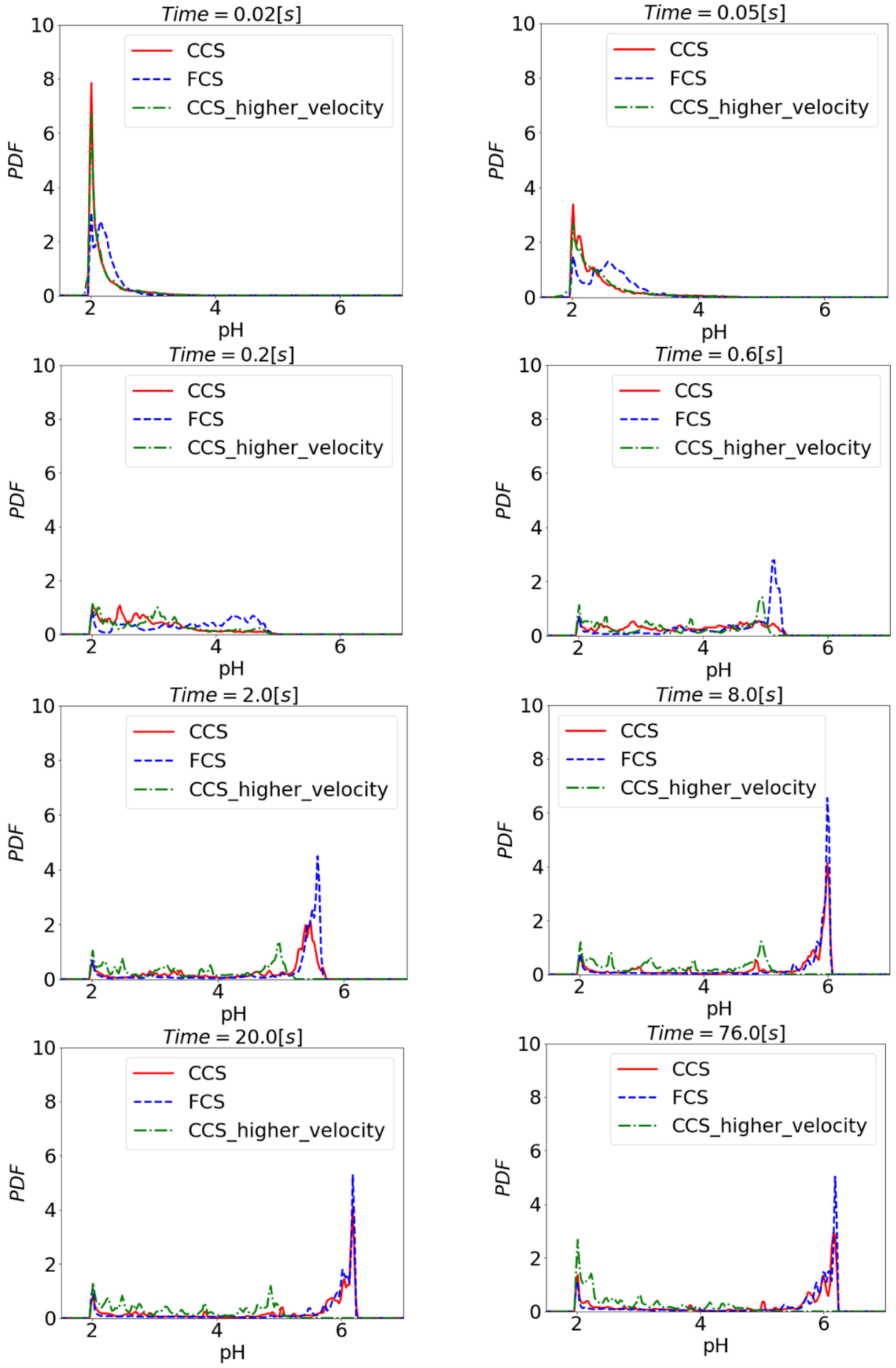

Figure 1. Temporal evolution of the PDF of the $\mathrm{pH}$ for CCS (the shale with coarse calcite grains), FCS (the shale with fine calcite grains), and CCS with higher velocity. Over time, the $\mathrm{pH}$ in the domain increases because of the calcite dissolution. The number of regions having higher $\mathrm{pH}$ values are larger for FCS compared to other cases. The case of CCS with higher velocity generally shows lower $\mathrm{pH}$ values, which is due to the short residence time of the HFF in the domain.

$$
\begin{aligned}
& R_{\text {pyrite }}\left(\mathrm{mol} \cdot \mathrm{m}^{-2} \cdot \mathrm{s}^{-1}\right) \\
& \quad=\left(10^{-8.19} a_{\mathrm{H}^{+}}{ }^{-0.11} a_{\mathrm{O}_{2}}{ }^{0.5}\right)\left(1-\Omega_{\text {pyrite }}\right) \\
& R_{\text {barite }}\left(\mathrm{mol} \cdot \mathrm{m}^{-2} \cdot \mathrm{s}^{-1}\right) \\
& \quad=\left(10^{-6.9} a_{\mathrm{H}^{+}}{ }^{0.22}+10^{-7.9}\right)\left(1-\Omega_{\text {barite }}\right)
\end{aligned}
$$

where $R_{\mathrm{m}}$ is the reaction rate of mineral $\mathrm{m}, a_{i}$ is the activity of the species $i$, and $\Omega_{\mathrm{m}}$ is the saturation ratio of the mineral $\mathrm{m}$. To calculate the amount of the minerals in (mol), $R_{\mathrm{m}}$ should be multiplied by the time step and also the reactive area of the minerals. In the LB method used in this study, the reactive area is computed on the basis of the number of faces of a solid grid cell, which is in contact with fluid. For instance, for a liquid 
grid cell, which is in contact with one calcite grid cell, the area is $\Delta x^{2}$, where $\Delta x$ is the size of the grid cell.

The fluid composition at the inlet is kept constant during the simulations, and it is assumed that the initial fluid composition is the same as the inlet. When the mass transfer equation is being solved, the no-flow boundary conditions are used at the top and bottom of the domain, whereas the zero diffusive-flux boundary condition is applied at the domain outlet. The diffusion coefficient of the chemical species is taken to be the same and equal to $10^{-9}\left(\mathrm{~m}^{2} \mathrm{~s}^{-1}\right)$. The fluid flow is driven by applying a constant pressure gradient across the domain. The value of the dynamic viscosity used for the fluid is $10^{-6}\left(\mathrm{~m}^{2}\right.$ $\left.\mathrm{s}^{-1}\right)$.

We look at the different properties of the system, such as the fluid chemistry, the mineral distributions, and the porositypermeability relation, to evaluate the impacts of the calcite spatial distribution, the calcite content, and the injection flow rate on the structural evolution of the shale samples.

\section{RESULTS AND DISCUSSION}

4.1. 2D Simulations. 4.1.1. Effect of Calcite Spatial Distribution and Flow Velocity. In our simulations, we focused only on the pore-scale spatial distribution of calcite because it is highly reactive under acidic conditions and its reaction rate is faster than other minerals. Different calcite spatial distributions in shale matrices can therefore lead to different patterns of the microstructural changes in shales. In what follows, we investigate what effluent chemistry, porositypermeability relations, and mineral distributions look like when the HFF is injected into CCS and FCS. Moreover, we also assess how a higher flow velocity influences the fluid chemistry, porosity-permeability relations, and mineral profile during HFF-shale interactions. To this end, we run another simulation for CCS, where the initial average velocity in the domain is $6.66 \times 10^{-5}\left(\mathrm{~m} \mathrm{~s}^{-1}\right)$.

4.1.1.1. Fluid Chemistry. Figure 1 shows the temporal evolution of the probability distribution function (PDF) of the $\mathrm{pH}$ for CCS and FCS. Initially at $t=0.02(\mathrm{~s})$, the PDFs indicate a peak at low $\mathrm{pH}$ values, which reveals that most of the regions in the domain have low $\mathrm{pH}$. Over time, the low $\mathrm{pH}$ solution reacts with calcite, and this causes the $\mathrm{pH}$ to rise $\left(\mathrm{Ca}^{2+}\right.$ level also increases as result of the calcite dissolution; see Figure S8 of the Supporting Information). The increase in the $\mathrm{pH}$ is evident from Figure 1 , at $t=0.05$ and $0.2(\mathrm{~s})$, where it demonstrates that the peaks at the low $\mathrm{pH}$ values are attenuated and a broader range for the $\mathrm{pH}$ can be observed. This increase in the $\mathrm{pH}$, which is because of the calcite dissolution, is similar to what was observed during the HFFshale reactions in the previous experiments. ${ }^{8}$ After $t=2.0(\mathrm{~s})$, the PDFs in Figure 1 show a peak at higher $\mathrm{pH}$ values, indicating that most parts of the domain now have $\mathrm{pH}$ values greater than 5 . This peak moves toward the higher $\mathrm{pH}$ values as simulations proceed further. During the later times of the simulation, in addition to the large peak at the higher $\mathrm{pH}$, a small peak at the lower $\mathrm{pH}$ starts growing, which represents the regions near the inlet where the low $\mathrm{pH}$ HFF, with $\mathrm{pH} \mathrm{2,} \mathrm{is}$ injected into the domain.

Figure 1 also demonstrates that generally the peaks at the higher $\mathrm{pH}$ values for FCS are larger than those of CCS. The difference between these peaks becomes smaller as the simulation time approaches $t=76(\mathrm{~s})$. One reason for this difference is that the reactive surface area of calcite in contact with the HFF for FCS is larger than the calcite reactive surface area for CCS. This can be observed in Figure 2, where it indicates that the total surface area of calcite for FCS is larger than the calcite reactive area for CCS.

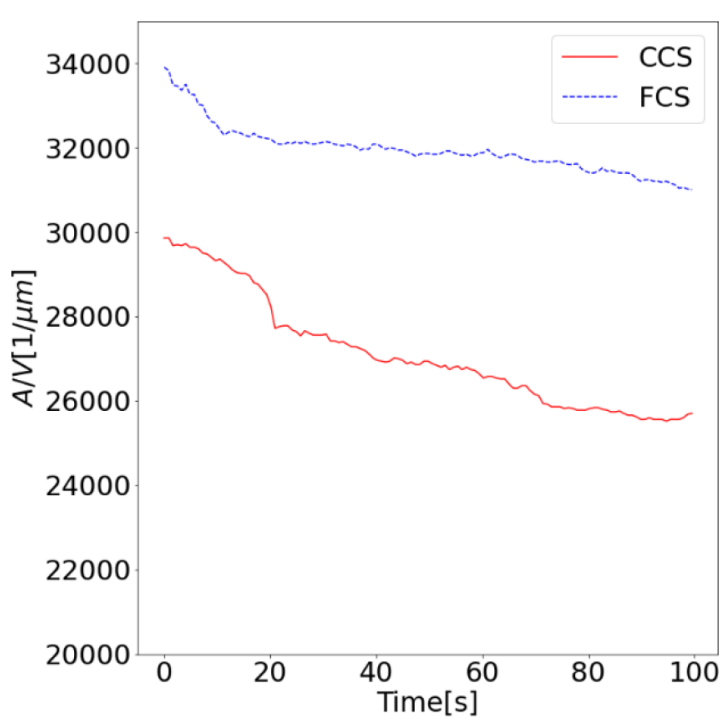

Figure 2. Temporal changes of the total reactive surface area of the calcite grains, in contact with the HFF, for CCS and FCS.

As observed in Figure 1, after $t=20.0(\mathrm{~s})$, the change in the $\mathrm{pH}$ for CCS and FCS is not significant. This is because the calcite saturation index, $\mathrm{SI}_{\text {calcite }}$ in the domain is approaching zero over time (see Figure S9 of the Supporting Information), implying that the solution is becoming saturated with respect to calcite, thus slowing the calcite dissolution rate and the $\mathrm{pH}$ change. This is consistent with the results from prior experiments reporting that $\mathrm{SI}_{\text {calcite }}$ approaches zero. ${ }^{8}$ For CCS with higher velocity, however, a different trend can be observed. As Figure 1 presents, after $t=20.0$ (s), the number of regions in the domain, having a low $\mathrm{pH}$, increases and a peak at the low $\mathrm{pH}$ appears in Figure 1 at $t=76.0(\mathrm{~s})$. Figure S9 of the Supporting Information also reveals that SI $_{\text {calcite }}$ for the case of CCS with higher velocity is still well below zero for different parts of the domain. This lower $\mathrm{pH}$ and lower $\mathrm{SI}_{\text {calcite }}$ results from the higher velocity of the flow, which reduces the residence time of the HFF in the domain and the low $\mathrm{pH}$ HFF at the inlet flows deeper into the domain and lowers the $\mathrm{pH}$.

In addition to calcite, pyrite also dissolves, releasing more $\mathrm{Fe}^{2+}$ into the solution (see Figure S10 of the Supporting Information). The amount of $\mathrm{Fe}^{2+}$ produced for FCS is generally higher than that for CCS. This could be explained by the difference in the $\mathrm{pH}$ for these two cases. As observed in Figure 1, the $\mathrm{pH}$ for FCS is generally higher than that for CCS, which according to the pyrite reaction rate equation (eq 22) causes a higher dissolution rate for pyrite and, hence, higher $\mathrm{Fe}^{2+}$ concentrations for FCS. For CCS with higher velocity, the $\mathrm{Fe}^{2+}$ concentration is generally lower than FCS and CCS, especially at the later simulation times. This is because the inlet solution, which is lacking any $\mathrm{Fe}^{2+}$, flows faster into the domain and flushes out produced $\mathrm{Fe}^{2+}$, and it decreases the $\mathrm{Fe}^{2+}$ concentration.

4.1.1.2. Mineral Reaction Patterns. As Figures 3 shows, most of the calcite dissolution in the shales occurs close to the inlet, where the $\mathrm{pH}$ is the lowest, and most of the calcite (gray color in Figure 3) in the other parts of the domain remain 

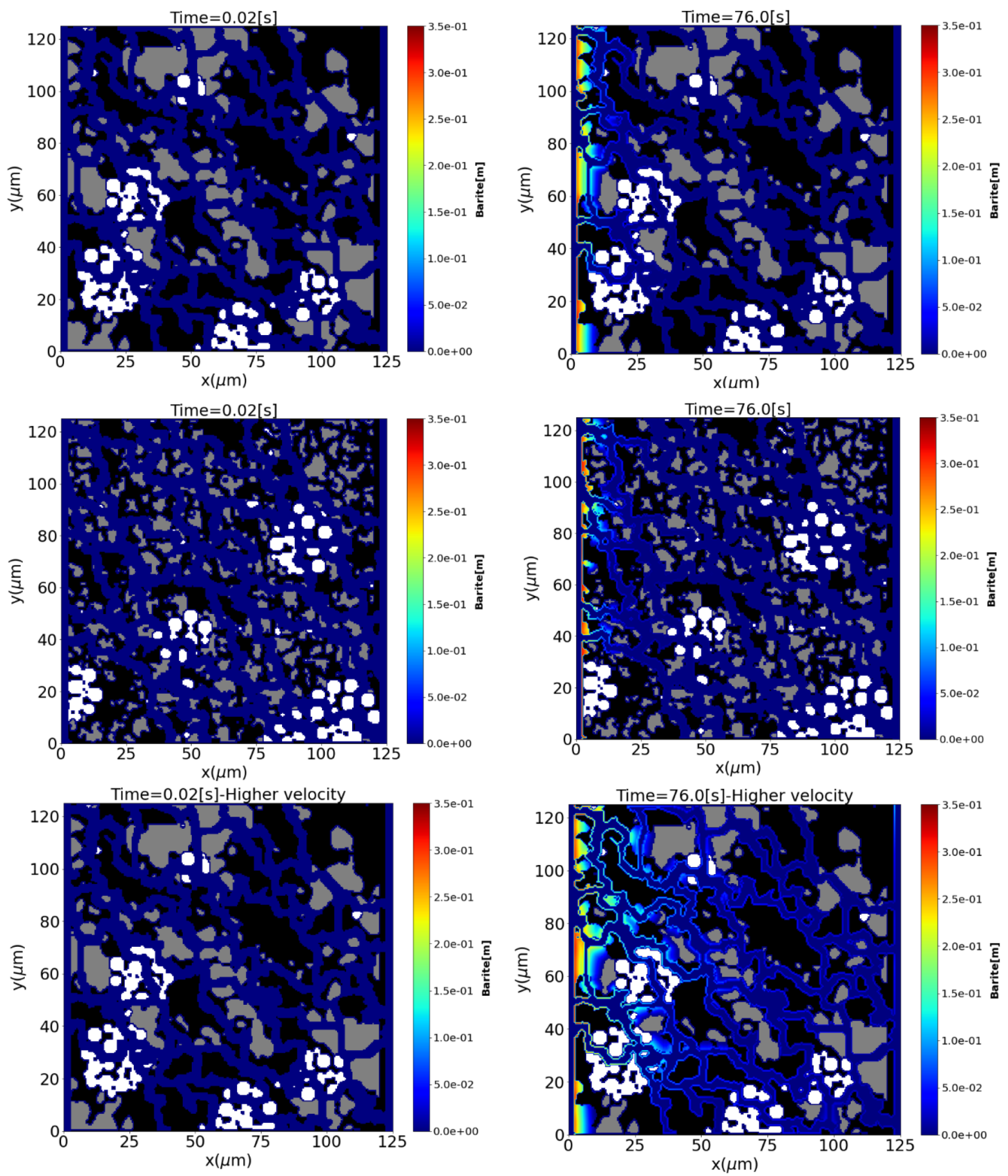

Figure 3. Amount of barite precipitated at 0.02 (s) (left column) and 76 (s) (right column) for CCS (first row), FCS (middle row), and CCS with higher velocity (last row). In the plots, the gray color denotes calcite, the black color denotes non-reactive minerals, and the white color denotes pyrite. Over time, few calcite surfaces near the inlet dissolve. While pyrite reacts with the HFF, its geometry evolution is not visible during the simulation time scale. As shown, little barite precipitation occurs near the inlet, where the influent solution is more supersaturated with respect to barite. For CCS, barite precipitation extends further into the domain, and increasing the velocity increases this penetration depth.

unaltered. This dissolution pattern is similar to the face dissolution patterns, which usually happen at low Peclet numbers. ${ }^{52}$ For the case of CCS with higher velocity, greater calcite dissolution along the flow direction can be observed. As presented in Figure 3, contrary to calcite, pyrite does not show any geometry evolution. Pyrite does react with the HFF, as confirmed by the $\mathrm{Fe}^{2+}$ concentration (Figure $\mathrm{S} 10$ of the Supporting Information), but the complete dissolution of the pyrite grains is not detectable during the time scale of the 

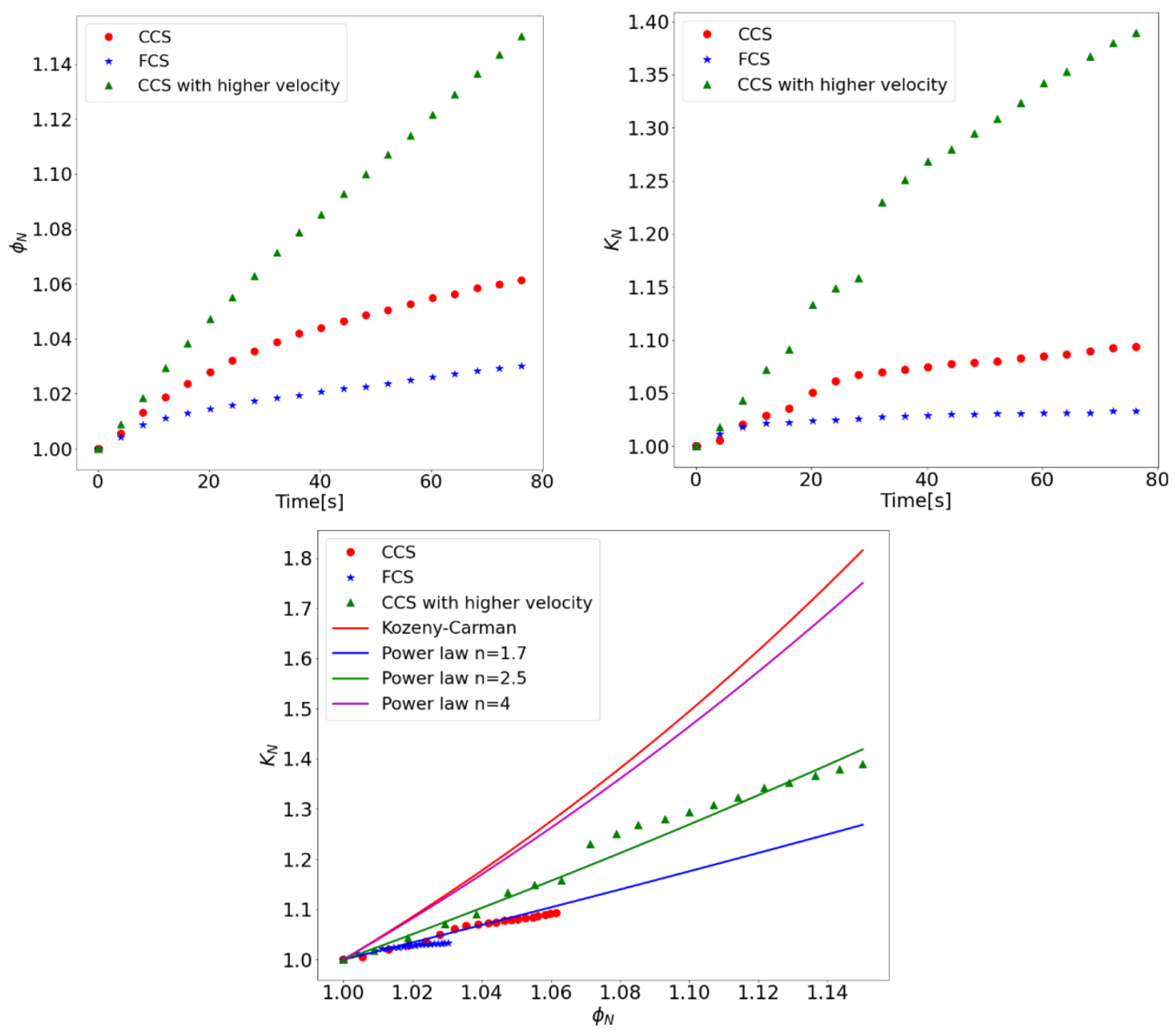

Figure 4. Plots of the normalized permeability versus time, normalized porosity versus time, and normalized permeability versus normalized porosity for CCS, FCS, and CCS with higher velocity. As shown, the permeability values of CCS are higher than those of FCS, which is clearly because of the greater extent of the calcite dissolution that occurred for CCS. Increasing the velocity leads to the higher permeabilities because greater calcite dissolution takes place when velocity is higher and the residence time of the HFF is shorter in the domain. The computed permeability values are compared to those calculated using the power law and Kozeny-Carman relations.

simulations. The slow reaction rate of pyrite is due to the lack of high concentrations of dissolved $\mathrm{O}_{2}$ in the influent.

The injected acidic solution is supersaturated with respect to barite. Barite therefore precipitates on the surfaces of the minerals present in the shales. In this study, we simulate the barite nucleation by assigning initial seeds or nuclei to all of the substrates, where these nuclei initiate the barite growth. The heterogeneous nucleation of barite therefore occurs on all of the substrates once the supersaturated solution is in contact with a mineral substrate. Figure 3 also presents the distribution of the precipitated barite in the system for FCS and CCS. As the simulation proceeds, more barite precipitates in the areas close to the inlet because of the access to the solution that is more supersaturated with respect to barite. It is evident that, for FCS, barite has mostly precipitated near the inlet, whereas for CCS, the barite precipitation front has penetrated into the domain, which is because of the calcite dissolution. The depth of penetration is even more when the supersaturated solution is injected at a higher velocity. This pattern is qualitatively similar to the barite precipitation patterns observed in previous studies, ${ }^{22}$ where they have shown that, for the calcite-rich Eagle ford shale samples, the barite precipitation front has extended into the shale matrix in contrast to the low-calcite-content
Marcellus shale, where the barite precipitation front is mainly limited at the HFF-matrix interface. It should be pointed out that, in our study, we observe more barite precipitation into the domain for the CCS because calcite dissolves and it provides a new porosity. The supersaturated solution can therefore penetrate more into the domain, and thus, barite can precipitate further down the domain. In the prior studies, ${ }^{24}$ however, the greater amount of barite precipitation into the shale matrix, observed for the calcite-rich shale, has been attributed to the effect of the higher $\mathrm{pH}$ on the deprotonation of $\mathrm{HSO}_{4}{ }^{-}$. It is reported that $\mathrm{HSO}_{4}{ }^{-}$is deprotonated at the near-neutral conditions, thus increasing the $\mathrm{SO}_{4}{ }^{2-}$ concentration, which leads to a higher rate for the barite precipitation. $^{22}$

4.1.1.3. Porosity-Permeability Relationship. The calcite dissolution and the barite precipitation change the porosity and permeability of the shale samples. Figure 4 represents the normalized permeability (permeability/initial permeability) and porosity (porosity/initial porosity) versus time and also the normalized permeability versus the normalized porosity for CCS, FCS, and CCS with higher velocity. The permeability values for the shales were calculated using the velocity profile. As evident from Figure 4, the permeability and porosity of the 

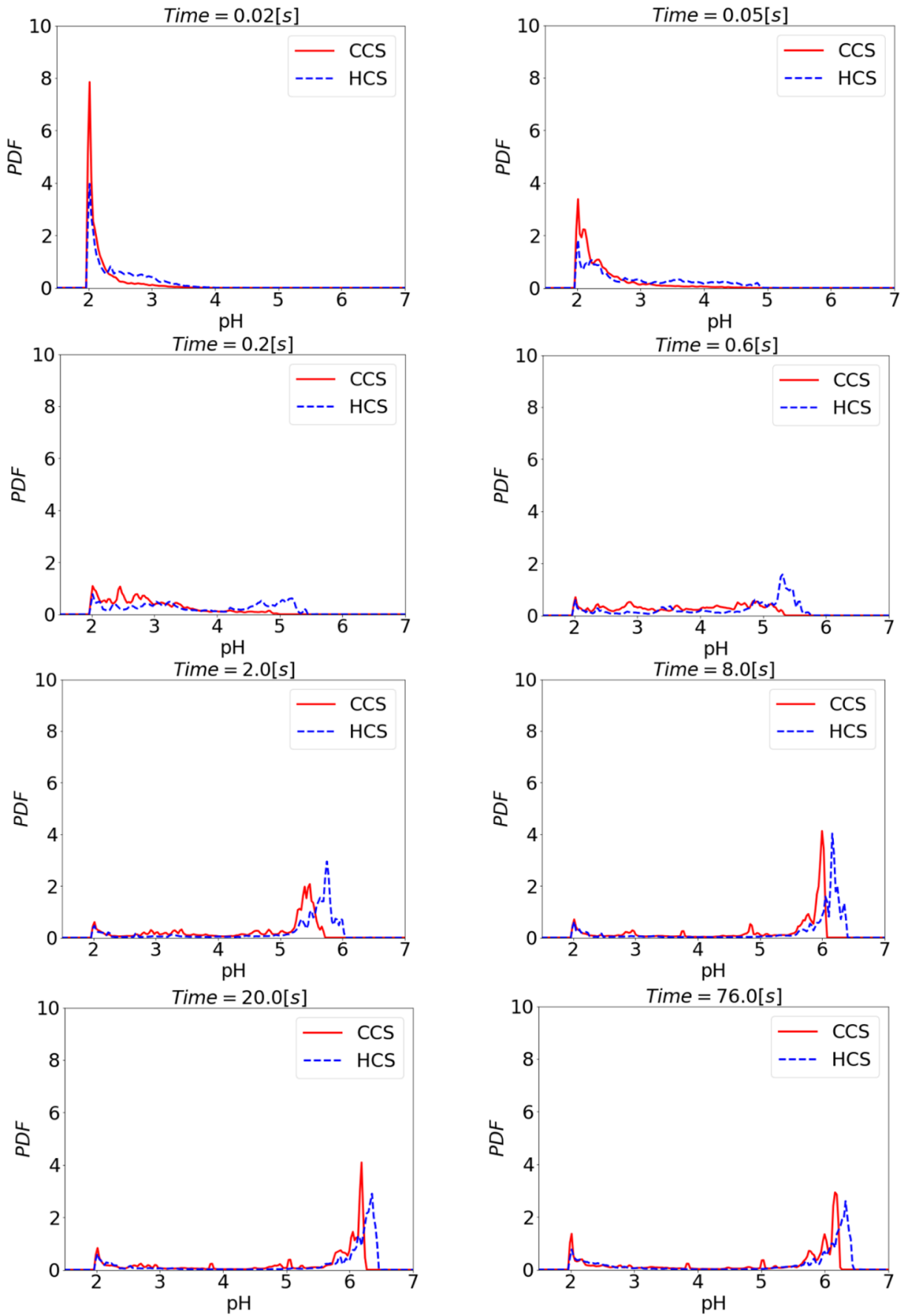

Figure 5. Temporal evolution of the PDF of the $\mathrm{pH}$ for CCS (the shale with coarse calcite grains) and HCS (the shale with higher calcite content). Over time, the $\mathrm{pH}$ in the domain increases because of the calcite dissolution. Because HCS has a higher calcite content, it generally exhibits higher $\mathrm{pH}$ values.

shales increase over time. Overall, the permeability values for CCS are higher than those for FCS. For CCS, the dissolution of calcite grains plays a more important role in increasing the permeability because the calcite grains are coarser and their dissolution leads to higher porosities and permeabilities, whereas for FCS, the grains are generally finer and their dissolution does not change the permeability as much as the dissolution of the coarser grains. As observed in Figure 3, increasing the flow velocity leads to greater dissolution of calcite grains along the flow direction, and this translates into higher permeabilities for the case of CCS with higher velocity.
As simulations proceed, the solution inside the domain tends to become saturated with respect to calcite, meaning that the calcite dissolution rate decreases. This also slows the rate of the permeability enhancement, which is clearly shown in Figure 4 at the later simulation times. This observation is not completely valid for CCS with higher velocity because, as Figure S9 of the Supporting Information shows, the solution in the domain is still undersaturated with respect to calcite and has the capacity to dissolve more calcite and increase the permeability further. 

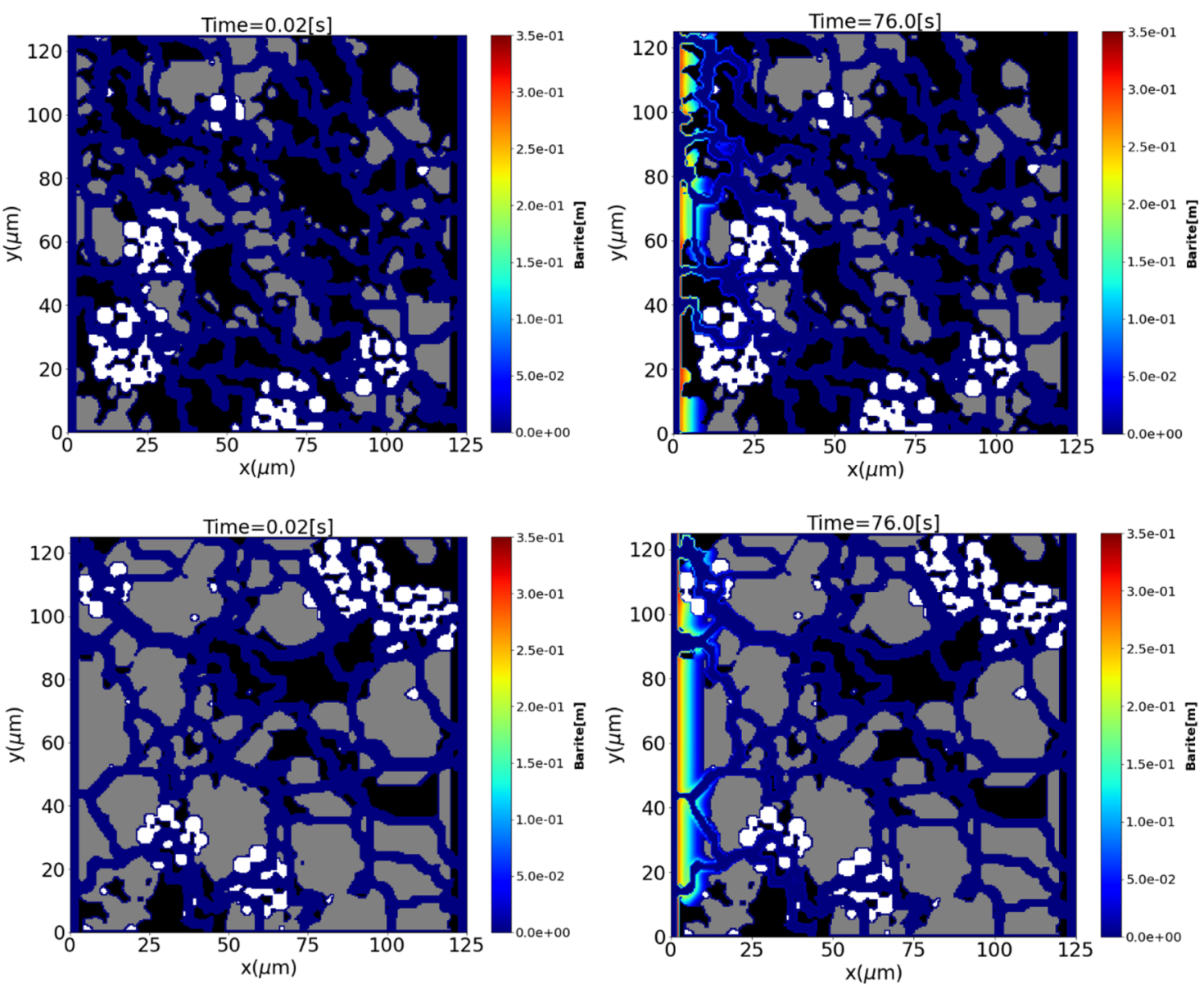

Figure 6. Amount of barite precipitated at 0.02 (s) (left column) and 76 (s) (right column) for CCS (first row) and HCS (second row). In the plots, the gray color denotes calcite, the black color denotes non-reactive minerals, and the white color denotes pyrite. Over time, few calcite surfaces near the inlet dissolve. While pyrite reacts with the HFF, its geometry evolution is not visible during the simulation time scale. As shown, little barite precipitation occurs near the inlet, where the influent solution is more supersaturated with respect to barite. For HCS, the extent of barite precipitation is more than that of CCS.

The normalized permeabilities calculated using the porescale simulations are also compared to the normalized permeabilities computed using the power law, $\left(k / k_{0}\right)=(\varphi /$ $\left.\varphi_{0}\right)^{n}$, and Kozeny-Carman, $\left(k / k_{0}\right)=\left(\varphi^{3} /(1-\varphi)^{2}\right)((1-$ $\left.\left.\varphi_{0}\right)^{2} / \varphi_{0}{ }^{3}\right)$, relations. As shown in Figure 4 , the KozenyCarman and power law with $n=4$ overestimate the normalized permeability values. The power law relation with $n=1.7$ can provide a better fit to the normalized permeabilities of CCS and FCS, and the power law relation with $n=2.5$ can better fit the normalized permeabilities of CCS with higher velocity. It should be pointed out that almost all of the relations would fail to fit the data during the later simulation times because, during the later times, the normalized permeability trend plateaus, and this plateau cannot be modeled with the power law relations. The normalized permeability trend shows this plateau because some of the minerals in the domain react very slowly, meaning that, although calcite dissolves, the presence of other minerals creates barriers to flow, which slows the permeability enhancement.

It should be mentioned that, during the simulations, although barite is precipitating, it has not yet contributed to the porosity and permeability of the shales because none of the simulation grid cells, in which barite is precipitating, has been completely filled with barite, so that the cell can be considered as a solid grid cell. The current model can indeed account for simultaneous dissolution and precipitation to occur. This means that we could then expect to see a more dynamic porosity-permeability relationship as a result of co-existence of the calcite dissolution and the barite precipitation. To be able to see this dynamic porosity-permeability relationship, the simulations would need to be run for longer times, which will be the focus of our future endeavor.

4.1.2. Effect of the Calcite Content. Previous experimental studies have shown that the different calcite contents in shale matrices can lead to different microstructural changes in shales. $^{21,22}$ This section will therefore deploy the built reactive transport model to assess how a different calcite content influences the alteration of the shale rock. To this end, we compare the results (fluid chemistry, porosity-permeability relations, and mineral profiles) from the CCS simulations to those from the HCS (having higher calcite content) simulations.

4.1.2.1. Fluid Chemistry. A higher calcite content in the shale matrix will generally results in higher $\mathrm{pH}$ values, as demonstrated in Figure 5. At the early times during the simulation, the $\mathrm{pH}$ in the domain is between 2 and 3. During the later times, most parts of the domain exhibit $\mathrm{pH}$ values greater than 5.5. As observed in Figure 5, at any given time, HCS shows higher $\mathrm{pH}$ values, which is clearly because of its higher calcite content. For HCS, this higher calcite content 

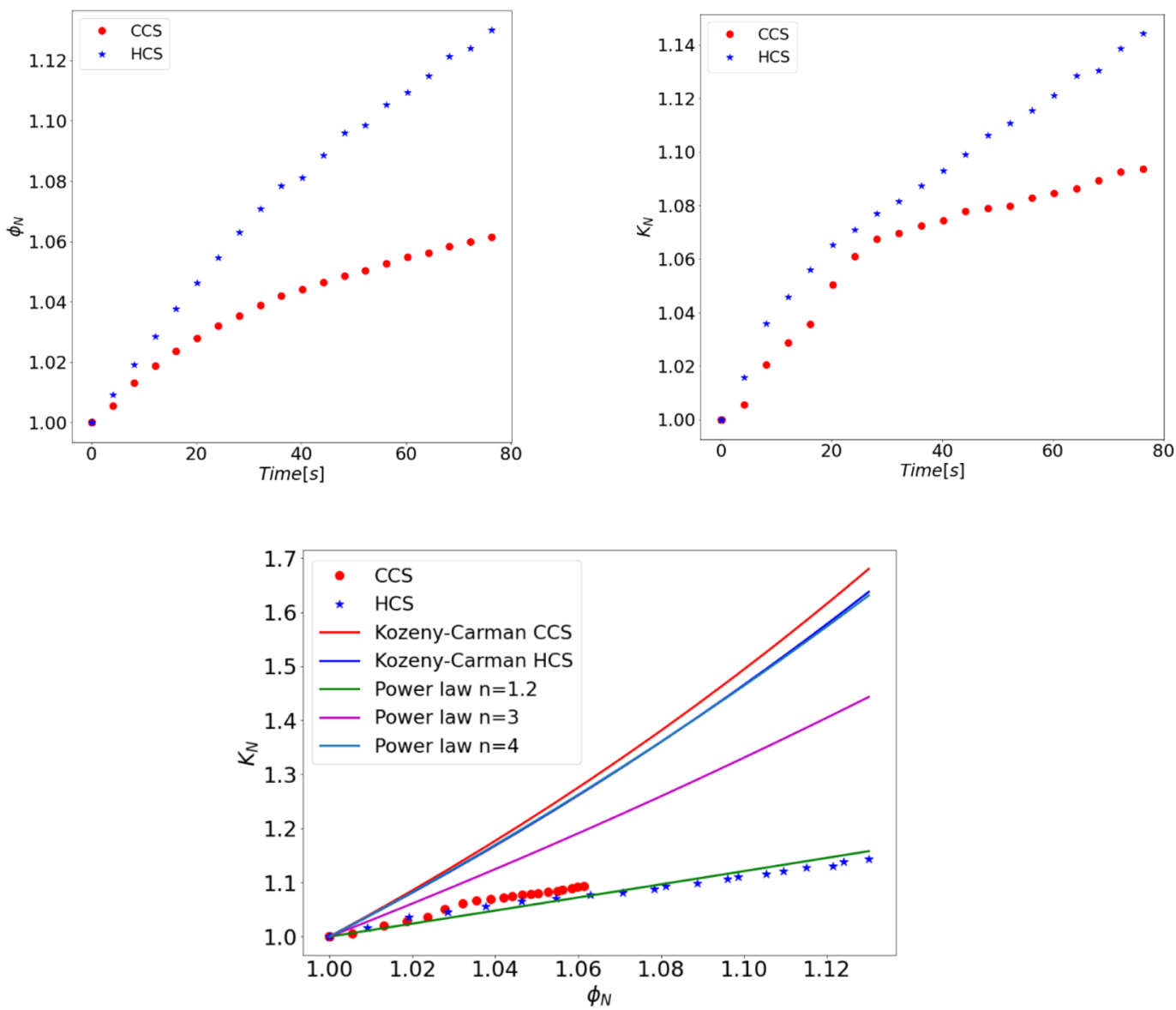

Figure 7. Plots of the normalized permeability versus time, normalized porosity versus time, and normalized permeability versus normalized porosity for CCS and HCS. As shown, the permeability values of HCS are higher than those for CCS at any given time, which is clearly because of the greater extent of calcite dissolution that occurred for HCS. In the normalized permeability versus normalized porosity, for a given normalized porosity, the normalized permeability of CCS is higher than that for HCS. This is because it takes more time for CCS to reach a certain porosity, and at this longer time, CCS has a higher normalized permeability compared to HCS, which takes a shorter time to reach the same normalized porosity. The computed permeability values are compared to those calculated using the power law and Kozeny-Carman relations.

also causes the solution to have a higher $\mathrm{SI}_{\text {calcite }}$ (see Figure $\mathrm{S} 11$ of the Supporting Information) as a result of the greater buffering capacity. The higher $\mathrm{pH}$, produced in the case of $\mathrm{HCS}$, also causes greater $\mathrm{Fe}^{2+}$ to be released into the solution, which is reflected as higher peaks of $\mathrm{Fe}^{2+}$ in Figure $\mathrm{S} 12$ of the Supporting Information.

4.1.2.2. Mineral Reaction Patterns. Figure 6 reveals that most of the calcite dissolution occurs near the inlet where the $\mathrm{pH}$ of HFF is low. In both CCS and HCS, the location of the calcite dissolution front is almost the same. This is also valid for the barite precipitation front; in both cases, the penetration depth of the barite precipitation is the same. However, as simulations proceed, both the location of the calcite dissolution and barite precipitation fronts for HCS will extend further because there are more calcite grains that can dissolve, and consequently, their dissolution allows the barite precipitation to move toward the outlet.

Another feature observed when barite precipitates is that the amount of barite precipitated on the non-reactive minerals is higher compared to the amount of barite precipitated on calcite (see the area surrounded by the red circle in Figure S13 of the Supporting Information for a comparison of the amount of barite precipitated on calcite and the non-reactive minerals). This is because the solution near the non-reactive minerals has a lower $\mathrm{pH}$, whereas the solution close to calcite has a higher $\mathrm{pH}$ caused by the calcite dissolution. The barite rate expression, used in this study, has an inverse relation with the $\mathrm{pH}$, meaning that, when the $\mathrm{pH}$ is lower, the barite precipitation rate will be higher. This is also consistent with the previous studies, showing that the barite precipitation rate is high at acidic conditions. ${ }^{53}$

Figure 6 also shows no significant pyrite dissolution because its dissolution rate is very slow considering the limited amount of dissolved oxygen in the influent.

4.1.2.3. Porosity-Permeability Relationship. Figure 7 presents the results of the evolution of the normalized permeability and normalized porosity for CCS and HCS. At any given time, the normalized permeability and normalized porosity for HCS are higher than those for CCS because HCS has a higher calcite content, which leads to greater calcite dissolution and, consequently, higher porosity and permeability values. As evident from Figure 7, the normalized porosity and normalized permeability initially experience a rather sharp increase, but later, the rate of change in $K_{\mathrm{N}}$ and $\phi_{\mathrm{N}}$ slows, which is due to the reduction in the calcite dissolution rate. This reduction is less pronounced for HCS because there are more calcite grains near the inlet and they can react with the acidic solution to create more porosity, which can also 
increase the permeability. The $K_{\mathrm{N}}$ versus $\phi_{\mathrm{N}}$ plot in Figure 7 indicates that, for a given $\phi_{\mathrm{N}}$, CCS exhibits a higher $K_{\mathrm{N}}$ than HCS. This is because the time that it takes for CCS to reach to a certain $\phi_{\mathrm{N}}$ is longer than that for HCS. HCS has a higher calcite content and can therefore reach that certain $\phi_{\mathrm{N}}$ by dissolving the greater amount of calcite within a shorter period of time. During this shorter time period, $K_{\mathrm{N}}$ for HCS still has not increased as much as that for CCS.

Figure 7 also demonstrates the comparison between the normalized permeability values calculated using the simulations to those computed using the Kozeny-Carman and power law relations. As evident from Figure 7, only the power law relation with $n=1.2$ can provide a better match. As mentioned before, during the later times, the stabilized normalized permeabilities cannot be predicted using the power law relations.

4.2. 3D Simulations. In comparison to the $2 \mathrm{D}$ simulations, simulations on the $3 \mathrm{D}$ shale geometry might provide better insights into the shale and the HFF chemical interactions because the reactive transport processes are modeled in 3D. To this end, we perform the $3 \mathrm{D}$ simulations and present some of the preliminary results related to the calcite dissolution and the barite precipitation in the $3 \mathrm{D}$ shale geometry in the early times during the simulations. The aim here is to show the capability of the pore-scale model to handle and simulate $3 \mathrm{D}$ geometries. This 3D model will be used in a future work to provide inputs for a multi-scale reactive transport model. The pore-scale model can provide the local or the small-scale information for the multi-scale reactive transport simulators. As a result of the existence of multiple length scales in the shale reservoirs, the multi-scale models are a better choice for simulating the largescale reactive transport processes in comparison to using only the pore-scale model or only the continuum scale model. In the development of the multi-scale models, the information related to the smaller scales needs to be incorporated into the multi-scale models. This information on the small scale can be provided by experiments ${ }^{54}$ or perhaps more easily by the porescale reactive transport modeling, as developed in this study.

For the 3D simulations, all of the boundary condition types remain the same as for the $2 \mathrm{D}$ simulations. In the following, we show the preliminary results of the analyses performed for the $3 \mathrm{D}$ simulation.

Figure 8 demonstrates the $\mathrm{Ca}$ concentration profile at $t=$ 0.02 and $6 \mathrm{~s}$. The increase in the Ca concentration at $t=6 \mathrm{~s}$ confirms the calcite dissolution reaction, which is also clear from the temporal evolution of the effluent $\mathrm{Ca}$ concentration (Figure 9a). The effluent $\mathrm{Ca}$ data in the 3D simulation also shows a plateau after an initial rather sharp increase in the effluent $\mathrm{Ca}$ concentration. The fluid $\mathrm{pH}$ level in the domain also starts to rise as a result of the calcite dissolution, as evident from Figure S14 of the Supporting Information, where $\mathrm{pH}$ has increased from the initial value of 2 to higher values. Figure $9 \mathrm{~b}$ also shows the effluent $\mathrm{pH}$ in the shale, where it indicates that the $\mathrm{pH}$ has been buffered. It is evident from Figure $9 \mathrm{~b}$ that the $\mathrm{pH}$ becomes stabilized over time, which is probably because of a reduction in the calcite dissolution rate in areas where the transport becomes diffusion-dominated.

The barite precipitation pattern for the 3D shale geometry is presented in Figure 10. Here, calcite, pyrite, and the nonreactive minerals are not shown to enable a better observation of the barite precipitated in the system. At $t=0.02 \mathrm{~s}$, barite has precipitated uniformly everywhere in the domain (Figure 10) because the initial solution is supersaturated with respect to

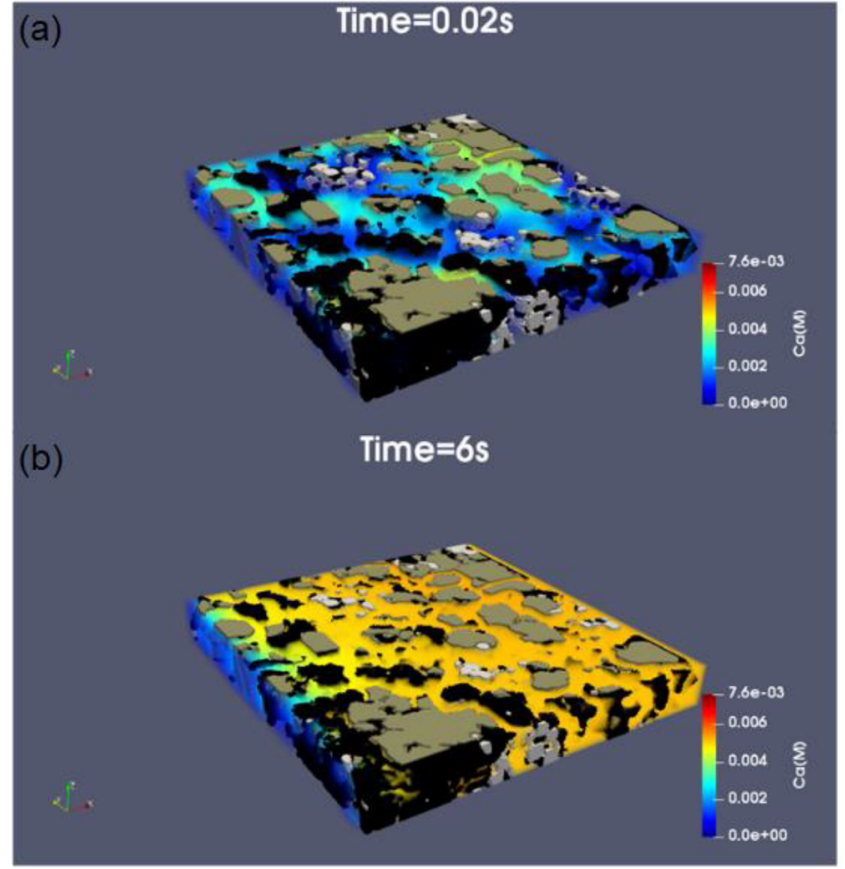

Figure 8. Ca concentration profile for the 3D simulation at $t=0.02$ and $6 \mathrm{~s}$. In the plots, the gray color denotes calcite, the black color denotes the non-reactive minerals, and the white color denotes pyrite. At $t=0.02 \mathrm{~s}$, the higher Ca concentration around the calcite surfaces indicates the calcite dissolution. At $t=6 \mathrm{~s}$, the Ca concentration has increased in most parts of the domain because of the further calcite dissolution and the transport of $\mathrm{Ca}$.

barite, and it has been assumed that the barite heterogeneous nucleation occurs on all of the solid substrates (calcite, pyrite, and the non-reactive minerals). At $t=6 \mathrm{~s}$, the extent of the barite precipitation decreases toward the outlet. The reason is that the regions near the inlet have access to the more fresh solution with the higher supersaturation with respect to barite, and this causes the more heterogeneous barite precipitation close to the inlet.

\section{CONCLUSION}

We build the $2 \mathrm{D}$ and $3 \mathrm{D}$ pore-scale reactive transport models to better understand how geochemical interactions between fracturing fluid and shale rock impact the transport properties of the shale rocks. In particular, we study the effect of the porescale calcite distribution on the evolution in the structure of representative shales when a fracturing fluid flows through fractured shale structures. Some of the 2D simulations were performed on two different shales with different calcite porescale distribution. The simulations were also carried out for the scenarios with higher flow rates.

We found from the $2 \mathrm{D}$ simulations that, during the HFFshale chemical interactions, the shale rock with the finer calcite grains exhibits higher $\mathrm{pH}$ values compared to the shale rock composed of the same amount of calcite but with the coarser grain sizes. Results also showed that the injection of the HFF with a higher velocity/rate results in lower $\mathrm{pH}$ values because of the shorter residence time for the HFF in the domain.

The injected HFF was supersaturated with respect to barite; therefore, barite precipitation occurred during the simulations. For the shale composed of the fine grains of calcite, barite precipitation mostly occurred near the inlet, but for the shale 


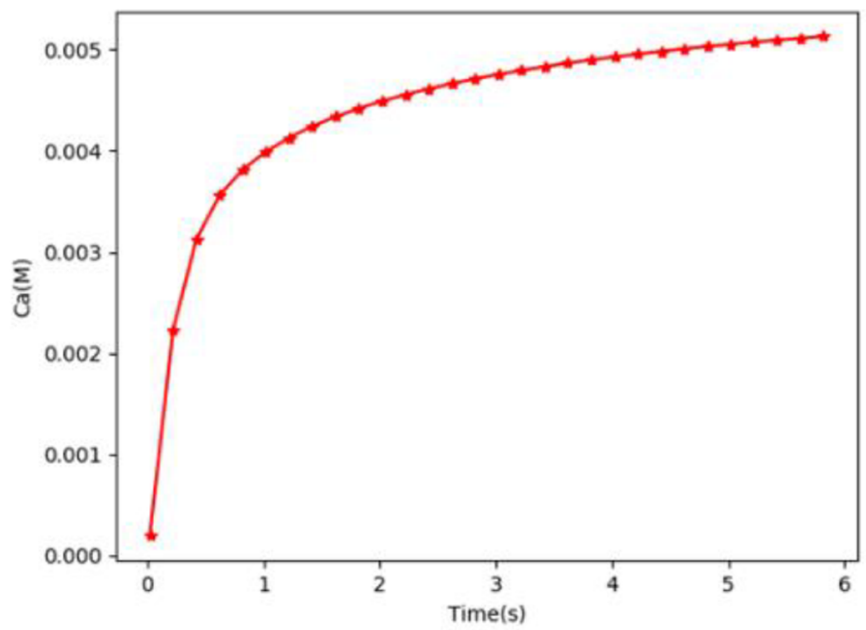

(a)

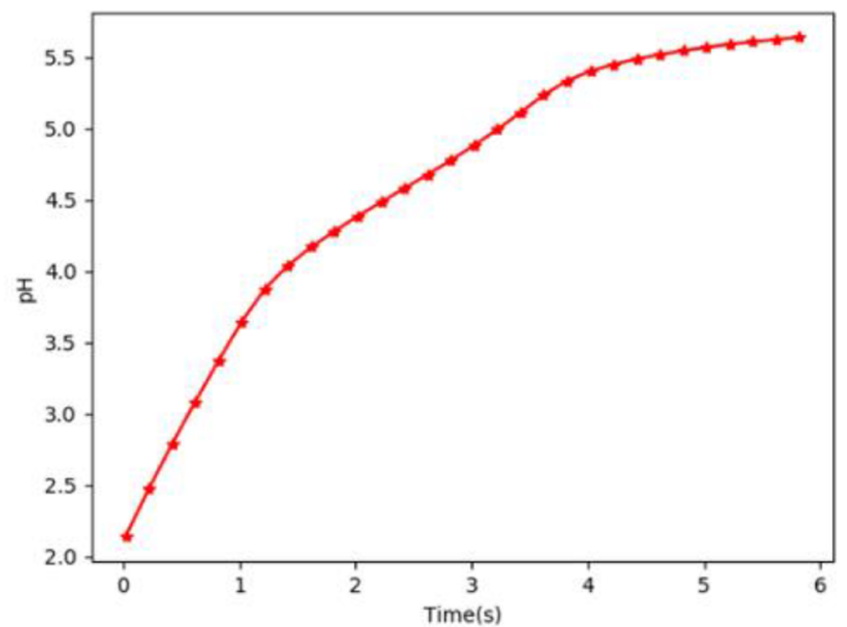

(b)

Figure 9. (a) Temporal evolution of the effluent Ca concentration for the $3 \mathrm{D}$ simulation. Early in the simulation, the Ca concentration shows a sharp increase, which is followed by a more stabilized trend caused by decreasing the calcite dissolution rate. (b) Temporal evolution of the effluent $\mathrm{pH}$ for the 3D simulation. As shown, the effluent $\mathrm{pH}$ increases as the result of the calcite dissolution, and this increasing trend seems to become stabilized over time.

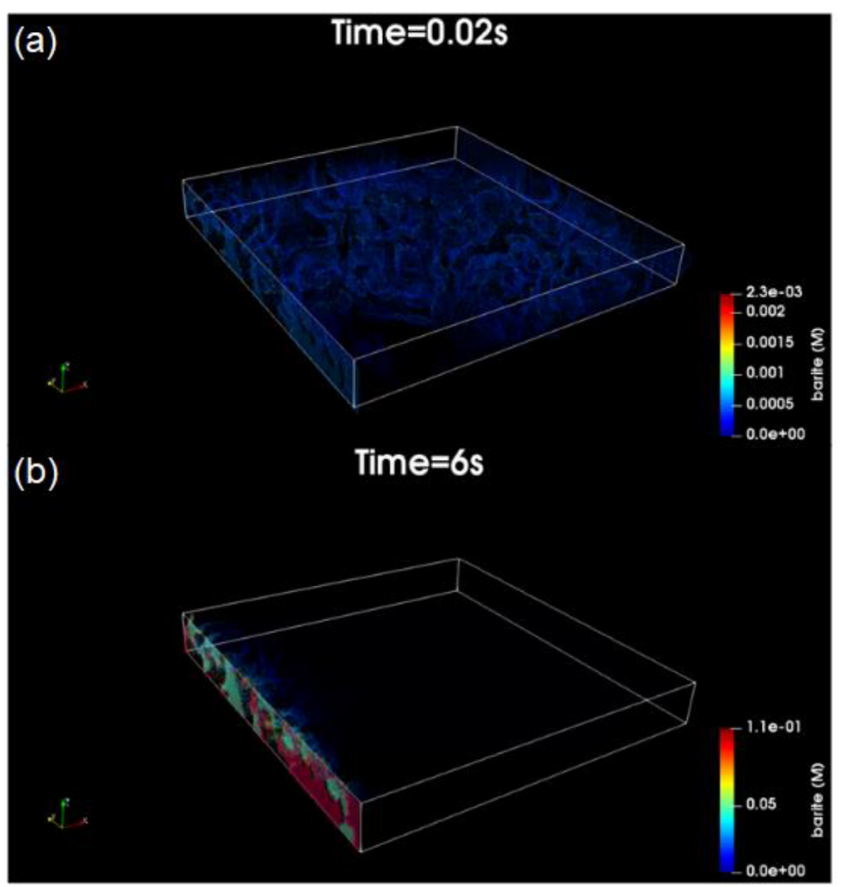

Figure 10. Amount of barite precipitated in the 3D shale sample at $t=$ 0.02 and $6 \mathrm{~s}$. The minerals are removed from the figure to facilitate the better observation of the barite precipitation. At $t=0.02 \mathrm{~s}$, a uniform barite precipitation pattern can be observed in the entire domain. At $t=6 \mathrm{~s}$, more barite precipitates near the inlet, where the solution has a higher supersaturation with respect to barite.

having coarser grains of calcite, the barite precipitation extended further down the domain. The results also demonstrated that injection of the HFF with higher velocity causes the barite precipitation front to extend more into the domain.

The results revealed that the permeability increase, triggered by calcite dissolution, is higher for the shale sample with the coarser calcite grains. This may be due to the emergence of more (and possibly larger) pathways made available by the dissolution in the samples with the larger calcite grains. We also found that the higher flow rate increases the permeability enhancement.

The $2 \mathrm{D}$ simulations were also run to study the effect of the calcite content on the alteration of the shales. The analysis of the fluid chemistry indicated that the samples with the higher calcite content can neutralize the acid $\mathrm{pH}$ (because of more calcite dissolution) faster than those with the lower calcite content. Results also showed that, for samples with the higher calcite content, the extent of barite precipitation in the shale rock is higher compared to the samples with the lower calcite content. This allows us to predict the long-term evolution of the transport properties during the fracturing process as a result of clogging.

We also showed the ability of the developed model to tackle the $3 \mathrm{D}$ simulations. Some preliminary $3 \mathrm{D}$ simulations of the HFF-shale interaction were presented. The $3 \mathrm{D}$ model will be used in our future work to provide inputs for upscaling methods, such as the upscaling techniques ${ }^{54}$ used to obtain continuous time random walk (CTRW) parameters at larger scales. This allows for upscaling of reactive transport processes from pore scales to larger scales.

\section{ASSOCIATED CONTENT}

\section{SI Supporting Information}

The Supporting Information is available free of charge at https://pubs.acs.org/doi/10.1021/acs.energyfuels.0c02975.

Figures showing the $2 \mathrm{D}$ and $3 \mathrm{D}$ mineralogy of the shales, figures indicating the PDFs of $\mathrm{SI}_{\text {calcite, }} \mathrm{Ca}^{2+}$, and $\mathrm{Fe}^{2+}$ for CCS, FCS, HCS, and CCS with higher velocity, figures indicating the $\mathrm{pH}$ and barite precipitated for $\mathrm{HCS}$ at time $=1(\mathrm{~s})$, and figures indicating the $\mathrm{pH}$ and velocity profiles for $3 \mathrm{D}$ simulations (PDF) 


\section{AUTHOR INFORMATION}

\section{Corresponding Authors}

Hossein Fazeli - School of Chemistry, University of Nottingham, Nottingham NG7 2RD, United Kingdom; Institute of GeoEnergy Engineering, Heriot-Watt University, Edinburgh EH14 4AS, United Kingdom; (1) orcid.org/00000001-6193-469X; Email: h.fazeli@hw.ac.uk

Masoud Babaei - Department of Chemical Engineering and Analytical Science, The University of Manchester, Manchester M1 3AL, United Kingdom; (1) orcid.org/0000-0002-42013489; Email: masoud.babaei@manchester.ac.uk

\section{Authors \\ Veerle Vandeginste - School of Chemistry, University of Nottingham, Nottingham NG7 2RD, United Kingdom; (1) orcid.org/0000-0003-0950-7089 \\ Arash Rabbani - Department of Chemical Engineering and Analytical Science, The University of Manchester, Manchester M1 3AL, United Kingdom \\ Bagus Muljadi - Department of Chemical and Environmental Engineering, University of Nottingham, Nottingham NG7 2RD, United Kingdom}

Complete contact information is available at: https://pubs.acs.org/10.1021/acs.energyfuels.0c02975

\section{Notes}

The authors declare no competing financial interest.

\section{ACKNOWLEDGMENTS}

This work was supported by the Natural Environment Research Council (Grant NE/R018030/1), which is gratefully acknowledged.

\section{REFERENCES}

(1) Kargbo, D. M.; Wilhelm, R. G.; Campbell, D. J. Natural Gas Plays in the Marcellus Shale: Challenges and Potential Opportunities. Environ. Sci. Technol. 2010, 44 (15), 5679-5684.

(2) Soeder, D. J.; Kappel, W. M. Water Resources and Natural Gas Production from the Marcellus Shale; United States Geological Survey (USGS): Reston, VA, 2009; Fact Sheet 2009-3032, DOI: 10.3133/ fs20093032.

(3) Andrews, I. J. The Carboniferous Bowland Shale Gas Study: Geology and Resource Estimation; British Geological Survey for Department of Energy and Climate Change: London, U.K., 2013.

(4) Herrmann, J.; Rybacki, E.; Sone, H.; Dresen, G. Deformation Experiments on Bowland and Posidonia Shale-Part I: Strength and Young's Modulus at Ambient and In Situ $p_{\mathrm{c}}-T$ Conditions. Rock Mech. Rock Eng. 2018, 51 (12), 3645-3666.

(5) Herrmann, J.; Rybacki, E.; Sone, H.; Dresen, G. Deformation Experiments on Bowland and Posidonia Shale-Part II: Creep Behavior at In Situ pc-T Conditions. Rock Mech. Rock Eng. 2020, 53 (2), 755-779.

(6) Harrison, A. L.; Jew, A. D.; Dustin, M. K.; Thomas, D. L.; JoeWong, C. M.; Bargar, J. R.; Johnson, N.; Brown, G. E., Jr.; Maher, K. Element release and reaction-induced porosity alteration during shalehydraulic fracturing fluid interactions. Appl. Geochem. 2017, 82, 4762.

(7) Jew, A. D.; Dustin, M. K.; Harrison, A. L.; Joe-Wong, C. M.; Thomas, D. L.; Maher, K.; Brown, G. E., Jr.; Bargar, J. R. Impact of organics and carbonates on the oxidation and precipitation of iron during hydraulic fracturing of shale. Energy Fuels 2017, 31 (4), 36433658 .

(8) Paukert Vankeuren, A. N.; Hakala, J. A.; Jarvis, K.; Moore, J. E. Mineral reactions in shale gas reservoirs: Barite scale formation from reusing produced water as hydraulic fracturing fluid. Environ. Sci. Technol. 2017, 51 (16), 9391-9402.

(9) Dieterich, M.; Kutchko, B.; Goodman, A. Characterization of Marcellus Shale and Huntersville Chert before and after exposure to hydraulic fracturing fluid via feature relocation using field-emission scanning electron microscopy. Fuel 2016, 182, 227-235.

(10) Liu, D.; Li, Y.; Agarwal, R. K. Numerical simulation of longterm storage of $\mathrm{CO}_{2}$ in Yanchang shale reservoir of the Ordos basin in China. Chem. Geol. 2016, 440, 288-305.

(11) Wang, L.; Fortner, J. D.; Giammar, D. E. Impact of water chemistry on element mobilization from Eagle Ford Shale. Environ. Eng. Sci. 2015, 32 (4), 310-320.

(12) Wilke, F. D.; Vieth-Hillebrand, A.; Naumann, R.; Erzinger, J.; Horsfield, B. Induced mobility of inorganic and organic solutes from black shales using water extraction: Implications for shale gas exploitation. Appl. Geochem. 2015, 63, 158-168.

(13) Barbot, E.; Vidic, N. S.; Gregory, K. B.; Vidic, R. D. Spatial and temporal correlation of water quality parameters of produced waters from Devonian-age shale following hydraulic fracturing. Environ. Sci. Technol. 2013, 47 (6), 2562-2569.

(14) Kekacs, D.; McHugh, M.; Mouser, P. J. Temporal and thermal changes in density and viscosity of Marcellus shale produced waters. J. Environ. Eng. 2015, 141 (12), 06015006.

(15) Marcon, V.; Joseph, C.; Carter, K. E.; Hedges, S. W.; Lopano, C. L.; Guthrie, G. D.; Hakala, J. A. Experimental insights into geochemical changes in hydraulically fractured Marcellus Shale. Appl. Geochem. 2017, 76, 36-50.

(16) Tasker, T. L.; Piotrowski, P. K.; Dorman, F. L.; Burgos, W. D. Metal associations in Marcellus shale and fate of synthetic hydraulic fracturing fluids reacted at high pressure and temperature. Environ. Eng. Sci. 2016, 33 (10), 753-765.

(17) Pilewski, J.; Sharma, S.; Agrawal, V.; Hakala, J. A.; Stuckman, M. Y. Effect of maturity and mineralogy on fluid-rock reactions in the Marcellus Shale. Environ. Sci.: Processes Impacts 2019, 21 (5), 845855.

(18) Herz-Thyhsen, R. J.; Kaszuba, J. P.; Dewey, J. C. Dissolution of Minerals and Precipitation of an Aluminosilicate Phase during Experimentally Simulated Hydraulic Fracturing of a Mudstone and a Tight Sandstone in the Powder River Basin, WY. Energy Fuels 2019, 33 (5), 3947-3956.

(19) Chen, Q.; Kang, Y.; You, L.; Yang, P.; Zhang, X.; Cheng, Q. Change in composition and pore structure of Longmaxi black shale during oxidative dissolution. Int. J. Coal Geol. 2017, 172, 95-111.

(20) Jew, A. D.; Harrison, A. L.; Kiss, A. M.; Dustin, M. K.; JoeWong, C.; Thomas, D. L.; Maher, K.; Brown, G. E., Jr.; Cercone, D.; Bargar, J. R. Mineralogical and Physical Changes that Control PoreScale Shale-Gas Properties. Proceedings of the SPE/AAPG/SEG Unconventional Resources Technology Conference (URTEC); Austin, TX, July 24-26, 2017; Paper URTEC-2708858-MS, DOI: 10.15530/ urtec-2017-2708858.

(21) Li, Q.; Jew, A. D.; Kiss, A. M.; Kohli, A.; Alalli, A.; Kovscek, A. R.; Zoback, M. D.; Cercone, D.; Maher, K.; Brown, G. E., Jr.; Bargar, J. R. Imaging Pyrite Oxidation and Barite Precipitation in Gas and Oil Shales. Proceedings of the SPE/AAPG/SEG Unconventional Resources Technology Conference (URTEC); Houston, TX, July 23-25, 2018; Paper URTEC-2902747-MS, DOI: 10.15530/urtec-2018-2902747.

(22) Li, Q.; Jew, A. D.; Kohli, A.; Maher, K.; Brown, G. E., Jr.; Bargar, J. R. Thicknesses of Chemically Altered Zones in Shale Matrices Resulting from Interactions with Hydraulic Fracturing Fluid. Energy Fuels 2019, 33 (8), 6878-6889.

(23) You, L.; Zhou, Y.; Kang, Y.; Cheng, Q.; Zhang, N. Experimental evaluation of oxidation sensitivity in organic-rich shale reservoir. J. Pet. Sci. Eng. 2020, 192, 107230.

(24) Li, Q.; Jew, A. D.; Brown, G. E.; Bargar, J. R.; Maher, K. Reactive Transport Modeling of Shale-Fluid Interactions after Imbibition of Fracturing Fluids. Energy Fuels 2020, 34 (5), 55115523. 
(25) Cai, Z.; Wen, H.; Li, L. Clay Distribution Patterns Regulate Natural Attenuation of Marcellus Shale Waters in Natural Aquifers. Energy Fuels 2018, 32 (9), 9672-9682.

(26) Li, Y.; Yang, S.; Liu, D.; Yang, C.; Yang, Z.; Li, H.; Tang, Z. Experimental study of shale-fluids interaction during oxidative dissolution with hydrogen peroxide, sodium hypochlorite and sodium persulfate. Appl. Geochem. 2020, 113, 104503.

(27) Osselin, F.; Saad, S.; Nightingale, M.; Hearn, G.; Desaulty, A.; Gaucher, E.; Clarkson, C.; Kloppmann, W.; Mayer, B. Geochemical and sulfate isotopic evolution of flowback and produced waters reveals water-rock interactions following hydraulic fracturing of a tight hydrocarbon reservoir. Sci. Total Environ. 2019, 687, 1389-1400.

(28) Pearce, J.; Turner, L.; Pandey, D. Experimental and predicted geochemical shale-water reactions: Roseneath and Murteree shales of the Cooper Basin. Int. J. Coal Geol. 2018, 187, 30-44.

(29) Zeng, L.; Reid, N.; Lu, Y.; Hossain, M. M.; Saeedi, A.; Xie, Q. Effect of the Fluid-Shale Interaction on Salinity: Implications for High-Salinity Flowback Water during Hydraulic Fracturing in Shales. Energy Fuels 2020, 34 (3), 3031-3040.

(30) Cai, Z.; Li, L. How long do natural waters "remember" release incidents of Marcellus Shale waters: A first order approximation using reactive transport modeling. Geochem. Trans. 2016, 17 (1), 6.

(31) Cai, Z.; Wen, H.; Komarneni, S.; Li, L. Mineralogy controls on reactive transport of Marcellus Shale waters. Sci. Total Environ. 2018, 630, 1573-1582.

(32) Vilcáez, J. Reactive transport modeling of produced water disposal into dolomite saline aquifers: Controls of barium transport. J. Contam. Hydrol. 2020, 233, 103600.

(33) Hommel, J.; Coltman, E.; Class, H. Porosity-permeability relations for evolving pore space: A review with a focus on (bio-) geochemically altered porous media. Transp. Porous Media 2018, 124 (2), 589-629.

(34) Poonoosamy, J.; Klinkenberg, M.; Deissmann, G.; Brandt, F.; Bosbach, D.; Mäder, U.; Kosakowski, G. Effects of solution supersaturation on barite precipitation in porous media and consequences on permeability: Experiments and modelling. Geochim. Cosmochim. Acta 2020, 270, 43-60.

(35) Prasianakis, N. I.; Curti, E.; Kosakowski, G.; Poonoosamy, J.; Churakov, S. V. Deciphering pore-level precipitation mechanisms. Sci. Rep. 2017, 7 (1), 13765.

(36) Seigneur, N.; Mayer, K. U.; Steefel, C. I. Reactive transport in evolving porous media. Rev. Mineral. Geochem. 2019, 85 (1), 197238.

(37) Vengosh, A.; Jackson, R. B.; Warner, N.; Darrah, T. H.; Kondash, A. A critical review of the risks to water resources from unconventional shale gas development and hydraulic fracturing in the United States. Environ. Sci. Technol. 2014, 48 (15), 8334-8348.

(38) Charlton, S. R.; Parkhurst, D. L. Modules based on the geochemical model PHREEQC for use in scripting and programming languages. Comput. Geosci. 2011, 37 (10), 1653-1663.

(39) Krüger, T.; Kusumaatmaja, H.; Kuzmin, A.; Shardt, O.; Silva, G.; Viggen, E. M. The Lattice Boltzmann Method: Principles and Practice; Springer, Cham: Cham, Switzerland, 2017; DOI: 10.1007/ 978-3-319-44649-3.

(40) Patel, R. A. Lattice Boltzmann method based framework for simulating physico-chemical processes in heterogeneous porous media and its application to cement paste. Ph.D. Thesis, Ghent University, Ghent, Belgium, 2016.

(41) Berryman, J. G. Relationship between specific surface area and spatial correlation functions for anisotropic porous media. J. Math. Phys. 1987, 28 (1), 244.

(42) Chen, D.; Teng, Q.; He, X.; Xu, Z.; Li, Z. Stable-phase method for hierarchical annealing in the reconstruction of porous media images. Phys. Rev. E 2014, 89 (1), 013305.

(43) Roberts, A. P. Statistical reconstruction of three-dimensional porous media from two-dimensional images. Phys. Rev. E: Stat. Phys., Plasmas, Fluids, Relat. Interdiscip. Top. 1997, 56 (3), 3203.

(44) Rabbani, A.; Ayatollahi, S. Comparing three image processing algorithms to estimate the grain-size distribution of porous rocks from binary $2 \mathrm{D}$ images and sensitivity analysis of the grain overlapping degree. Special Topics Rev. Porous Media 2015, 6 (1), 71-89.

(45) Rabbani, A.; Babaei, M. Image-based modeling of carbon storage in fractured organic-rich shale with deep learning acceleration. Fuel 2021, 299, 120795.

(46) Ougier-Simonin, A.; Renard, F.; Boehm, C.; Vidal-Gilbert, S. Microfracturing and microporosity in shales. Earth-Sci. Rev. 2016, 162, $198-226$.

(47) Ye, Y.; Wu, C.; Zhai, L.; An, Z. Pyrite morphology and episodic euxinia of the Ediacaran Doushantuo Formation in South China. Sci. China: Earth Sci. 2017, 60 (1), 102-113.

(48) Rabbani, A.; Babaei, M.; Javadpour, F. A triple pore network model (T-PNM) for gas flow simulation in fractured, micro-porous and meso-porous media. Transp. Porous Media 2020, 132 (3), 707740.

(49) Fan, W. The Influence of Water-Rock Interaction on Trace Element Mobilization during Shale Gas Production. Ph.D. Thesis, University of Michigan, Ann Arbor, MI, 2018.

(50) Palandri, J.; Kharaka, Y. A Compilation of Rate Parameters of Water-Mineral Interaction Kinetics for Application to Geochemical Modeling; United States Geological Survey (USGS): Reston, VA, 2004; Open-File Report 2004-1068, DOI: 10.3133/ofr20041068.

(51) Williamson, M. A.; Rimstidt, J. D. The kinetics and electrochemical rate-determining step of aqueous pyrite oxidation. Geochim. Cosmochim. Acta 1994, 58 (24), 5443-5454.

(52) Kang, Q.; Chen, L.; Valocchi, A. J.; Viswanathan, H. S. Porescale study of dissolution-induced changes in permeability and porosity of porous media. J. Hydrol. 2014, 517, 1049-1055.

(53) Ruiz-Agudo, C.; Putnis, C. V.; Ruiz-Agudo, E.; Putnis, A. The influence of $\mathrm{pH}$ on barite nucleation and growth. Chem. Geol. 2015, 391, 7-18.

(54) Muljadi, B. P.; Bijeljic, B.; Blunt, M. J.; Colbourne, A.; Sederman, A. J.; Mantle, M. D.; Gladden, L. F. Modelling and upscaling of transport in carbonates during dissolution: Validation and calibration with NMR experiments. J. Contam. Hydrol. 2018, 212, $85-95$. 